\title{
Transplantation of Retinal Pigment Epithelium Using a Pars Plana Approach
}

\author{
C. LANE, M. BOULTON and J. MARSHALL \\ London
}

\begin{abstract}
Summary
We describe a pars plana approach for transplantation of autologous retinal pigment epithelial cells from a peripheral chorioretinal biopsy to prepared Bruch's membrane at the posterior pole of the same eye. The technique has potential application in research and could be clinically applicable in the treatment of senile macular degeneration.
\end{abstract}

Tissue transplantation is an expanding medical field in which corneal grafting has traditionally been the ophthalmic surgeon's prime interest. However recent successes using neuronal cells, such as substantia nigra homografts ${ }^{1}$ and adrenal medullary autografts $^{2,3}$ in the treatment of Parkinson's disease, have stimulated further research into retinal transplants. Such transplants have potential use in the treatment of a variety of retinal dystrophies and degenerations affecting the photoreceptors and the retinal pigment epithelium (RPE). Both the RPE and photoreceptors are of neuroectodermal origin and are accessible for transplantation in the mature human retina. We have chosen to study transplantation of RPE because it is the simpler tissue with which to establish a technique. In addition it is easily visualised because of pigmentation and mature cells can readily be grown in tissue culture prior to transplantation. ${ }^{4}$

RPE transplantation in two animal species has previously been researched by Gouras. In the first cultured human RPE cells were injected onto Bruch's membrane in an owl monkey using an open sky technique. ${ }^{5} \mathrm{~A}$ severe inflammatory reaction, suggestive of acute rejection, : ensued. In the rabbit homologous cells were injected through a micropipette into the subretinal space using a closed system. ${ }^{6}$ RPE cell attachment and focal recovery of overlying retina was demonstrated. However, neither model was directly applicable to the clinical situation. Use of the open sky technique with a retinal flap prevented reattachment of undamaged retina in the monkey model and the rabbit eye had limitations as a model of the human eye. Firstly, there are few retinal blood vessels and secondly, rabbit RPE cells have large lipid globules which may affect their dynamics.

In order to use a model which had closer similarity to the human eye, we chose to assess the technical feasibility of RPE transplantation in the pig eye. This has a very similar retinal structure and blood supply to the human eye, although there is no macula or fovea. ${ }^{7,8,9}$ The miniature pig was chosen for ease of long term follow-up and autologous grafts were used to avoid tissue rejection. Cells from primary cultures were chosen to optimise cellular morphology and metabolic function, which become less consistent in subcultures. ${ }^{10}$

\section{Method}

\section{Retinal Detachment}

Access to the RPE was achieved using a pars plana approach. A localised retinal detachment of 3 to 5 disc diameters was produced 
by steady injection of a jet of $0.05 \mathrm{ml}$ of Dulbecco's phosphate buffered saline without calcium and magnesium (PBSA) against the inner retina through the 30 gauge port of a fibreoptic diathermy tissue manipulator ${ }^{11}$ (Fig. 1). This is similar to the technique initially described in rabbits. ${ }^{12}$ In the miniature pig retinal reattachment spontaneously occurred within $2-5$ days. ${ }^{13}$

Preliminary transplantation experiments were performed using homologous cells and the final series of eight experiments was performed using autologous cells from a chorioretinal biopsy.

\section{Preparation of Donor Cells}

A chorioretinal biopsy was obtained using a technique similar to that described by Peyman. ${ }^{14}$ A scleral flap was retracted and isobutyl cyanoacrylate glue (Histacryl, Cyanamid) was applied directly to the exposed choroid. Using the hardened glue for fixation, a $3.5 \mathrm{~mm}$ square of choroid, RPE and retina was excised using Vanna's scissors and placed in culture medium at room temperature this consisted of MEM, supplemented with $20 \%$ fetal calf serum. The medium was cooled to $4^{\circ} \mathrm{C}$ for transport to the laboratory. Cortical vitreous was abscised and the scleral wound was repaired using $8 / 0$ ethilon. Subconjunctival injections of $2 \mathrm{mg}$ betamethasone and $20 \mathrm{mg}$ gentamicin were given.

RPE cells were isolated and grown in tissue culture from the biopsy as described pre-

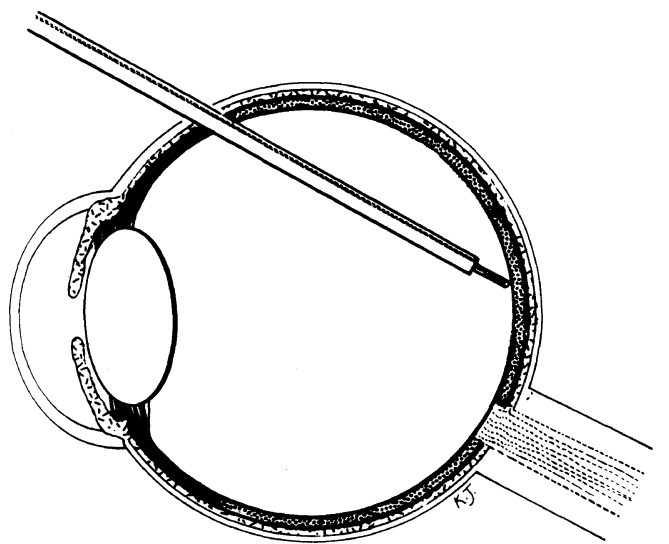

Fig. 1. Pars plana approach for the induction of retinal detachment. viously. ${ }^{15}$ Pure primary cultures of RPE cells in microtitre plates were radiolabelled using $0.2 \mathrm{uCi} / \mathrm{ml}$ of methyl-3H-thymidine, ${ }^{5}$ added to the medium one week prior to the estimated time of reaching confluence. Cell culture was necessary to amplify cell numbers, but primary cultures were chosen to optimise cellular morphology and metabolic function. ${ }^{10}$ In the most recent series a second label of a cell suspension of carbon particles was added to the medium 24 hours prior to confluence.

\section{Transplantation}

The recipient site was prepared at the posterior pole of the same eye. Bruch's membrane was denuded to avoid apex to apex orientation of donor to host RPE. This has been reported by Anderson in the cat ${ }^{16}$ and observed by ourselves in localised areas of retinal detachment in the miniature pig and prevents satisfactory function of overlying photoreceptors. To debride a localised area a retinal detachment was induced and the port of the manipulator was immediately advanced through the retinotomy. Injection of a jet of $0.05 \mathrm{ml}$ PBSA against the RPE resulted in a localised area of debridement, 1 to $3 \mathrm{~mm}$ in diameter. Immediately after preparation of the recipient site the manipulator was withdrawn. A suspension of $100 \mu l$ of trypsinised RPE cells, containing only approximately 4000 cells in order to avoid multilayers, was injected into the subretinal space using a $27^{i}$ gauge needle. The sclerotomy was repaired and eyes were fixed in $4 \%$ glutaraldehyde and processed for light microscopy and autoradiography 5 at 1 hour ( 3 eyes), 4 hours ( 2 eyes), 4 days, 7 days and 6 months after transplantation.

\section{Results}

Three principal aspects of this technique for transplantation of small numbers of autologous cells in the miniature pig eye revealed significant problems. Firstly, although the process of retinal detachment was usually atraumatic, reattached retina did not completely return to normal (Fig. 2). Secondly, preparation of the recipient site resulted in neat separation of host cells from Bruch's membrane in most cases (Fig. 3), but the 


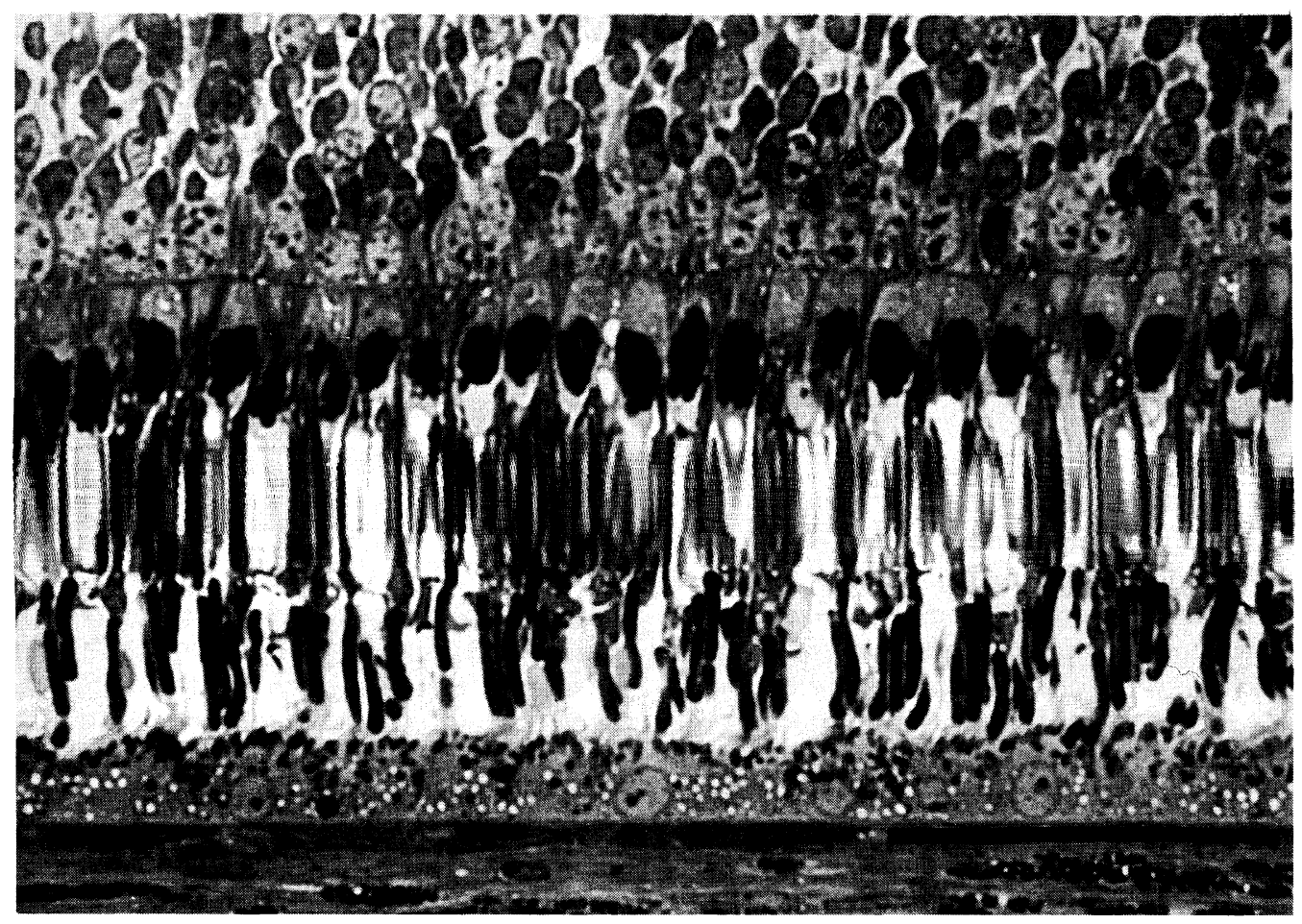

Fig. 2. Light micrograph of reattached retina two days after detachment. Note: vacuolation of the inner portion of the photoreceptor outer segments with some pyknotic nuclei and prominent apical microvilli on the RPE. Bar marker 50um.

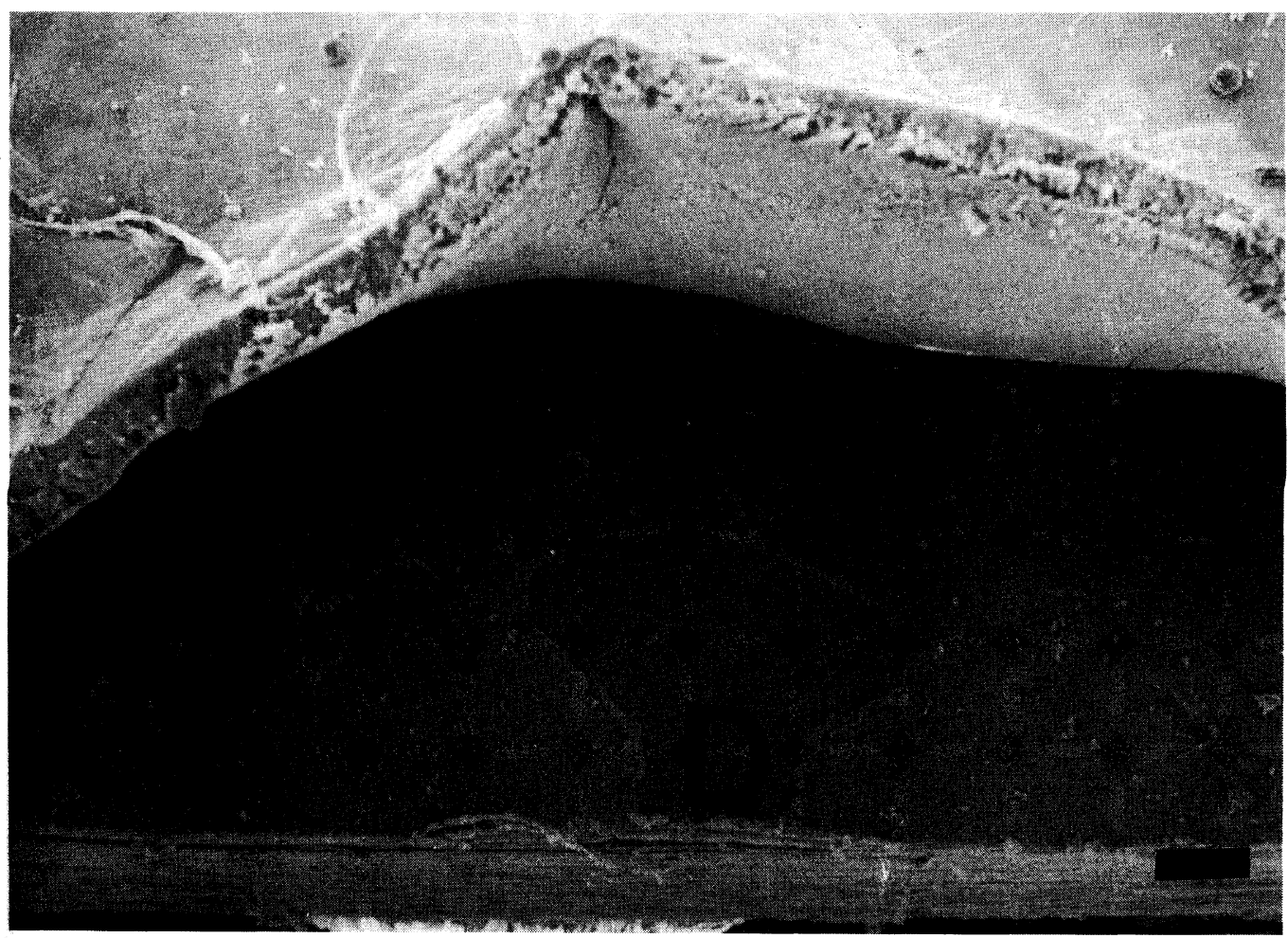

Fig. 3. Scanning electron micrograph showing denuded area (D) of Bruch's membrane underlying retinal detachment. Bar marker $200 \mu \mathrm{m}$. 
denuded area was variable, frequently very near to the retinotomy site, and associated with microscopic haemorrhage. Thirdly, delivery of RPE cells into a pool of sub-retinal fluid was inconsistent. In a few cases transplanted cells, most readily recognised by the intra-cytoplasmic carbon granules, were seen lying on Bruch's membrane (Fig. 4). However, there was a tendency for transplanted cells to lie near the edge of the retinal detachment, well away from the central debrided area, and occasional cells were also identified in the vitreous cavity and along the inner limiting membrane. Although transplanted cells on Bruch's membrane were identifiable up to 4 hours, subretinal haemorrhage and an inflammatory infiltrate formed a barrier, preventing attachment of donor cells in two cases prepared 4 and 7 days after transplantation. Donor cells have not been identified at sections from 6 months after autologous transplantation. Hence, reattachment of healthy overlying photoreceptors has not yet been demonstrated in this model.

\section{Discussion}

These results suggest that considerable practical difficulties exist with attempts to transplant RPE cells into the posterior pole using closed intraocular microsurgery. To overcome these it will be essential to refine instrumentation to reduce the risk of haemorrhage and to minimise damage caused to overlying retina by detachment. In addition it would be essential to optimise delivery of RPE cells to the central debrided area of Bruch's membrane.

In a rat model fresh pigmented donor RPE cells have recently been transplanted over intact host albino pigment epithelium without preparatory retinal detachment and with focal morphological recovery of overlying photoreceptors. ${ }^{17}$ Because of the host's albinism this could be performed transclerally into the retinal periphery with adequate visualisation. Although such a simple technique may have reduced the degree of trauma to the overlying retina in the miniature pig, choroidal haemorrhage is more

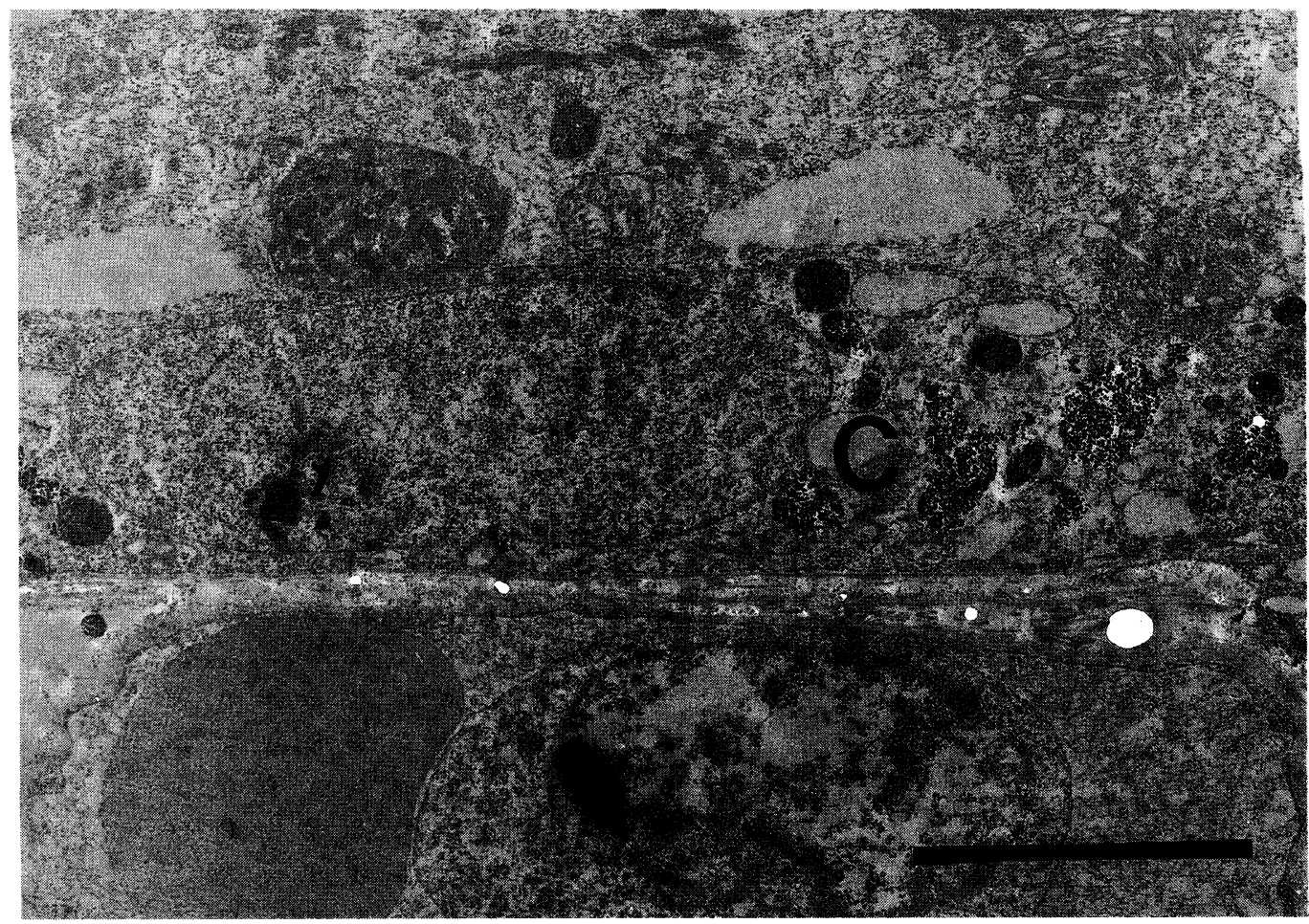

Fig. 4. Electron micrograph of carbon $(C)$ labelled RPE cell lying on Bruch's membrane 1 hour after transplantation. Many red blood corpuscles (RBC) are seen. Bar marker $5 \mu \mathrm{m}$. 
likely and visualisation of transplanted cells would not be possible in the pigmented animal. Moreover, an internal approach is preferable for access to the macula, where transplantation has greatest potential and avoidance of damage to Bruch's membrane and the choriocapillaris is critical. However, the use of an external approach avoids deposition of pigment epithelial cells in the vitreous cavity, an event which may predispose to the development of proliferative vitreoretinopathy. ${ }^{18}$

Vitrectomy was not performed in this model because the retina reattached rapidly with the vitreous in place. Even if vitrectomy had been performed in this model, it is unlikely to have been complete. Pig vitreous is very thick and the cortical vitreous gel is firmly attached to the inner retina, so total removal of this part of the vitreous without damage to the underlying retina would have proved difficult. In the adult human eye detachment of the posterior vitreous gel and vitrectomy are factors which could well improve cell delivery to the subretinal space. Two other elements may also increase the success rate in the human eye. Firstly, Bruch's membrane in the adult is significantly thicker than in the young miniature pig and may be more resistant to trauma. Secondly the use of a site which has already been prepared by a disease process would avoid traumatic denudement of Bruch's membrane. If the technique is further refined to a stage at which it could be used on the human eye, when could it be applied?

Malfunction of the RPE has been implicated in certain retinal dystrophies. There are isolated reports of excess amounts of lipofuscin and similar degradation products in the sub-retinal space or RPE in LawrenceMoon-Biedl syndrome, ${ }^{19}$ fundus flavimaculatus ${ }^{20}$ and Best's disease. ${ }^{21}$ This is consistent with the appearance of a dark choroid on fluorescein angiography and could reflect defective phagocytosis. Clinically an RPE defect is suggested by a flat EOG in Best's disease $^{21}$ and early pigment loss in choroideremia $^{22}$ These dystrophies do not severely affect central vision until adulthood or later and RPE transplantation would have to be performed before the onset of signific- ant photoreceptor degeneration. The potential use here would be minimal, but, if the technique could be applied to the transplantation of photoreceptors, it could prove useful in treating retinal dystrophies. Present research into transplantation of photoreceptors is at a very early stage. ${ }^{23,24}$

RPE transplantation, using autologous cells, could be applied to the treatment of macular degeneration. The occurrence of disciform lesions is related to alterations in Bruch's membrane and accumulation of debris between the RPE and choroid with choroidal neovascularisation. ${ }^{25}$ Present treatment using laser photocoagulation is destructive and has limited application. ${ }^{26}$

Miller et $a l .{ }^{27}$ have demonstrated that its effect may be related to the formation of tight junctions between proliferated RPE cells over a neovascular membrane, so the transplantation of RPE cells into this area could potentially seal off a neovascular complex. The peripheral retina is relatively preserved ${ }^{26}$ healthy RPE cells from this area may potentially be used as donor tissue.

\section{References}

${ }^{1}$ Dunnet SB, Björklund A, Steveni U, Iversen SD: Grafts of embryonic substantia nigra reinnervating the ventrolateral striatum ameliorate sensorineural impairments and akinesia in rats with 6-OHDA lesions of the nigrostriatal pathway. Brain Res 1981, 229: 209-17.

2 Madrazo I et al.: Open microsurgical autografts of adrenal medulla to the right caudate nucleus in two patients with intractable Parkinson's disease New Eng J Med 1987, 316: 831-4.

${ }^{3}$ Morrison KE: Brain transplantation - still fantasy? Discussion paper. J Roy Soc Med 1987, 80: 441-4.

${ }^{4}$ Edwards RB: Culture of mammalian retinal pigment epithelium and neural retina. In Methods in Enzymology Vol 81: Visual pigments and purple membranes, L. Packer ed., New York Academic Press 1982: 39-43.

5 Gouras P, Flood MT, Kjeldbye H, Bilek MK, Eggers $\mathrm{H}$ : Transplantation of cultured retinal epithelium to Bruch's membrane of the owl monkey's eye. Curr Eye Res 1985, 3: 253-65.

${ }^{6}$ Lopez R, Gouras P, Brittis M, Kjeldbye H: Transplantation of cultured rabbit retinal epithelium to rabbit retina using a closed eye method. Invest Ophthalmol Vis Sci 1986, 28: 1131-7. 
${ }^{7}$ Bloodworth JMB, Gutgesell HP, Engerman RL: Retinal vasculature of the pig. Light and electron microscopic studies. Exp Eye Res 1965, 4: 174-8.

${ }^{8}$ Rootman J: Vascular system of the optic nerve head and retina in the pig. Br J Ophthalmol 1971, 55: 808-19.

${ }^{9}$ Beauchemin ML: The fine structure of the pig's retina. Albrecht $v$ Graefes Arch Klin Exp Ophthalmol 1974, 190: 27-45.

${ }^{10}$ Newsome DA: Retinal pigment epithelium culture: current applications. Trans Ophthalmol Soc UK 1983, 103: 458-66.

${ }^{11}$ McCuen B, Hickingbotham D: A fibreoptic tissue manipulator for use in vitreous surgery. Am J Ophthalmol 1984, 98: 803-4.

${ }^{12}$ Foulds WS: Experimental retinal detachment. Trans Ophthalmol Soc UK 1963, 83: 153-70.

${ }^{13}$ Lane $\mathrm{CM}$ and Boulton ME: Retinal pigment epithelial transplantation: technique and possible applications. In Retinitis Pigmentosa: patient's fight for sight. F Brunsmann \& $R$ von Gyzycki eds. Advances in the Biosciences Vol 63, Pergamon Journals Ltd. 1987: 125138.

${ }^{14}$ Peyman G, Fishman G, Sanders D, Apple D, Vichek J: Biopsy of human scleral chorio-retinal tissue. Invest Ophthalmol Vis Sci 1975, 14: $707-10$

${ }^{15}$ Lane CM, Boulton M, Marshall J, Bird AC: Growth of pure cultures of retinal pigment epithelial cells using chorio-retinal biopsies from the pig. Exp Eye Res 1988, 46: 813-17.

${ }^{16}$ Anderson DH, Guerin CJ, Erickson PA, Stern WH, Fisher SK: Morphological recovery in the reattached retina. Invest Ophthalmol Vis Sci 1986, 27: 168-83.
${ }^{17}$ Lin-Xi L and Turner JE: Transplantation of retinal pigment epithelium to immature and adult rat hosts. Short and long term survival characteristics. Invest Ophthal Vis Sci Suppl 1988, 29: 46 .

${ }^{18}$ Machemer R: Pathogenesis and classification of massive preretinal proliferation. $\mathrm{Br} J$ Ophthalmol 1978, 62: 737-47.

${ }^{19}$ Runge P, Calver D, Marshall J, Taylor D: Histopathology of mitochondrial cytopathy and Laurence-Moon-Biedl syndrome. $\mathrm{Br} \quad J$ Ophthalmol 1970: 782-96.

${ }^{20}$ Eagle RC, Lucier AC, Bernardino VB, Yanoff M: Retinal pigment epithelial abnormalities in fundus flavimaculatus. Ophthalmology 1980, 87: 1189-200.

${ }^{21}$ Weingeist TA, Kobrin JL, Watzke RC: Histopathology of Best's macular dystrophy. Arch Ophthalmol 1982, 100: 1108-14.

${ }^{22}$ Lewis RA, Nussbaum RL, Ferrell R: Mapping $\mathrm{X}$-linked diseases: provisional assignment of the locus for choroideremia to Xq13-q24. Ophthalmology 1985, 92: 800-5.

${ }^{23}$ Gass JDM: Pathogenesis of disciform detachment of the neuro-epithelium III: Senile disciform macular degeneration. Am J Ophthalmol 1967, 63: 617-44.

${ }^{24}$ Coscas G: Montgomery Lecture: Subretinal neovascularisation in senile macular degeneration. Eye 1987, 1: 364-78.

${ }^{25}$ Miller H, Miller B, Ryan SJ: The role of retinal pigment epithelium in the evolution of subretinal neovascularisation. Invest Ophthalmol Vis Sci 1986, 27: 1644-52.

${ }^{26}$ Sarks SH: New vessel formation beneath the retinal pigment epithelium in senile eyes. $\mathrm{BrJ}$ Ophthalmol 1973, 57: 951-65. 